\title{
OPTIMIZATION OF WIRE EDM PROCESS BY USING TAGUCHI METHOD
}

\section{SARVESH SHIVANAND RANE ${ }^{1}$, VENKATESH BANNIGOLA ${ }^{2} \&$ B. V. BABU KIRAN ${ }^{3}$}

${ }^{1,2}$ Assistant Professor, Sri Venketeshwara College of Engineering, Bangalore, Karnataka, India

${ }^{3}$ Associate Professor, Sri Venketeshwara College of Engineering, Bangalore, Karnataka, India

\section{ABSTRACT}

The objective of this experimental work is, to study the effect of the input process parameters on the output parameters using Wire Electric Discharge Machining (WEDM) process. The input process parameters selected in this experimentation were Voltage, Pulse ON time, Pulse OFF time, Current, Bed Speed. The output process parameters against which the effect of the input process parameters obtained were Material Removal Rate (MRR) and Surface Roughness $(\mathrm{R} a)$. The test material selected in order to study effect of input parameters on the output parameters was D3 Grade Tool Steel. Taguchi method was used to formulate the design of experiments, so as to obtain optimum combination of the parameters, which were to be investigated in this study. Analysis of Variance (ANOVA) is used to analyze the effect of input process parameters on the machining characteristics and analyze the optimal process parameters of EDM which maximize the material removal rate (MRR) and minimize the surface roughness (Ra). The study reveals that the proper combination of input parameters in order to study the effect on the output parameters has its important role in the machining by using Wire Electric Discharge Machining (WEDM).

KEYWORDS: WEDM, MRR, Ra, ANOVA \& Taguchi Orthogonal Array

Received: Feb 27, 2018; Accepted: Mar 20, 2018; Published: Apr 11, 2018; Paper Id.: IJMPERDAPR2018158

\section{INTRODUCTION}

Electric Discharge Machining is a Nontraditional thermal metal removal process, which removes the unwanted material by means of erosion. The unwanted material gets removed due to the thermal energy which is generated in the electric spark. The material gets removed from the work piece by the process of erosion. Sparks occurring at high frequency, continuously and effectively remove the material from the work piece.

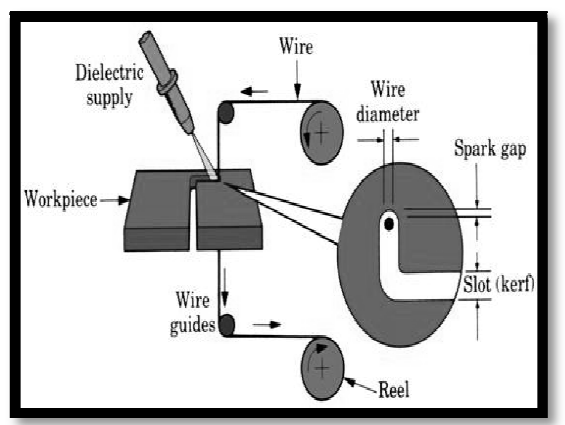

Figure 1: Wire Electric Discharge Machining Process

The dielectric fluid used in this experimental work is Demineralised water. The dielectric fluid acts as an insulator as well as a cooling agent. The electric discharge melts and vaporizes the minute amount of the material, which are then ejected and flushed away by the dielectric fluid during the process. The design of experiments 
followed in this experimentation was taguchi method. Orthogonal array were formulated, so as to obtain optimum combination of input process parameters against the output parameters. Analysis of Variance (ANOVA) is used to determine optimum value and its relative effect of each input parameters on the output responses.

\section{LITERATURE SURVEY}

G. Selvakumar et al. (2014) [1] studied experimental investigation on the optimization of WEDM process using 5083 aluminum alloy. Process parameter considered were pulse ON time, pulse OFF time, peak current and wire tension. The response factors were cutting speed and surface roughness. Results showed that cutting speed was independent on wire tension and surface roughness was independent on pulse OFF time and wire tension.

R. Chalisgaonkar et al. (2014) [2] in his research work developed a multi response optimization technique using traditional utility method in association with weight assignment concept. The effect of the process parameters such as wire type, pulse ON time, pulse OFF time, peak current, wire feed, servo voltage and wire offset were investigated on MRR, surface roughness and wire weight consumption. The conformation experiments results were carried out and the optimal values of the responses were validated.

S. Sivakiran et al. (2012) [3] studied the effects of the process parameters on MRR in WEDM of En 31 steel. The influence of various machining parameters pulse ON time, pulse OFF time, bed speed and current at four different levels on the response factor MRR was studied. Regression analysis was used to predict the MRR. The results indicated that current was the most effective parameter followed by pulse ON time, bed speed and pulse OFF time for an increased MRR. Experimental values and the predicted values were in good agreement.

H. Singh et al. (2009) [4] studied the effects of the input parameters on MRR in Wire EDM process. Influence of various process parameters like pulse ON time, gap voltage, pulse OFF time, peak current and wire tension. MRR was the output parameter. The results indicated that MRR increases with increase in peak current and pulse ON time, while decreases with increase in pulse OFF time and servo voltage. Pulse ON time had direct effect on the MRR.

\section{EXPERIMENTAL METHODOLOGIES}

\section{Machine Tool}

The machining operations were performed on SINO KA-300 model wire cut EDM machine. The EDM machine is installed at Concord United Products Pvt. Ltd. For experimentation purpose, the electrode material used was molybdenum wire of $0.18 \mathrm{~mm}$ diameter. The dielectric fluid used in this was DM (Demineralised Water). AISI grade D3 Tool Steel was the target material for the experimentation.

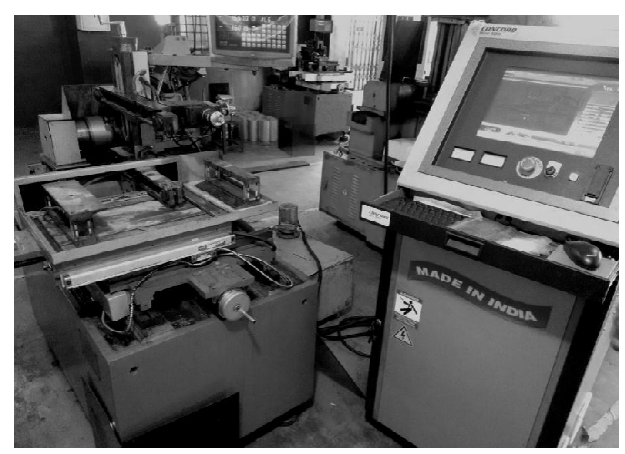

Figure 2: SINO KA-300 Wire Electric Discharge Machine 


\section{Material Selection}

Tool steel refers to a variety of carbon and alloy steels that are particularly well suited to be made into tools. D3 is an air hardening, high carbon and high chromium tool steel. They possess the properties such as hardness, resistance to abrasion and deformation. Tool steel has the unique ability to hold a cutting edge at elevated temperatures. They have good abrasion/wear resistance and have good dimensional stability and high compressive strength.

The size of the work piece considered for experimentation on wire cut EDM is $20 \times 10 \times 10 \mathrm{~mm}$.

Table 1: Chemical Composition of the Work piece

\begin{tabular}{|l|c|}
\hline \multicolumn{2}{|c|}{ AISI-D3 Tool Steel } \\
\hline \multicolumn{1}{|c|}{ Elements } & Specifications (\%) \\
\hline Chromium & 12.07 \\
\hline Carbon & 2.059 \\
\hline Silicon & 0.39 \\
\hline Manganese & 0.42 \\
\hline Phosphorous & 0.020 \\
\hline Sulphur & 0.017 \\
\hline Nickel & 0.06 \\
\hline Vanadium & 0.02 \\
\hline Tungsten & 0.18 \\
\hline
\end{tabular}

\section{Taguchi Design Approach}

In this experimentation, work was carried out using taguchi technique. L18 orthogonal array was used to get optimum combination of set of parameters. Taguchi's orthogonal array approach gives the best set of combination for the process parameters against the output response. The original response values are transformed into S/N ratio values. Further analysis is carried out based on these $\mathrm{S} / \mathrm{N}$ ratio values.

Table 2: Process Parameters and Their Levels

\begin{tabular}{|l|l|l|c|c|c|}
\hline \multicolumn{2}{|c|}{ Parameters } & \multirow{2}{*}{ Units } & \multicolumn{3}{|c|}{ Levels } \\
\cline { 4 - 6 } \multicolumn{2}{|c|}{} & & I & II & III \\
\hline $\mathrm{A}$ & Voltage & volts & 75 & 100 & --- \\
\hline $\mathrm{B}$ & Pulse ON time & $\mu \mathrm{sec}$ & 25 & 35 & 45 \\
\hline $\mathrm{C}$ & Pulse OFF time & $\mu \mathrm{sec}$ & 9 & 12 & 15 \\
\hline $\mathrm{D}$ & Current & $\mathrm{amps}$ & 2 & 4 & 6 \\
\hline $\mathrm{E}$ & Bed speed & $\mu \mathrm{m} / \mathrm{sec}$ & 75 & 150 & 225 \\
\hline
\end{tabular}

\section{Analysis of Variance (ANOVA)}

Analysis of Variance (ANOVA) was performed in order to study the significance of the process variables. The output parameters in the present experimental work were Material Removal Rate and Surface Roughness.

ANOVA analysis was carried out in the Minitab software and the results are discussed below. The table 2 shows the p-value known as probability value, which is less than 0.05 (alpha value). It shows that all the parameters are significant in the machining operation that was carried out.

The material removal rate is a higher performance characteristic, since the maximization of the quality characteristic of interest is sought and can be expressed as:

$\operatorname{MRR}=-10 \log (\Sigma(1 / \mathrm{y} 2) / \mathrm{n})$ 
The surface roughness is the lower-the performance characteristic and the loss function for the same can be expressed as:

$$
\mathrm{Ra}=-10 \log (\Sigma \mathrm{y} 2 / \mathrm{n})
$$

\section{Material Removal Rate}

Material removal rate (MRR) can be calculated using the equation;

$$
\operatorname{MRR}=\frac{(2 * \mathbf{W g}+\mathbf{D}) * \mathbf{t} * \mathbf{L}}{\mathbf{T}}
$$

Where,

$$
\begin{aligned}
& \mathrm{W}_{\mathrm{g}}=\text { spark gap - "0.02 mm" } \\
& \mathrm{D}=\text { Diameter of wire - "0.18 mm" } \\
& \mathrm{T}=\text { Time taken to cut "min" } \\
& \mathrm{L}=\text { Distance travelled by tool - " } 60 \mathrm{~mm} " \\
& \mathrm{t}=\text { Thickness of work piece - " } 10 \mathrm{~mm} "
\end{aligned}
$$

\begin{tabular}{|c|c|c|c|c|c|}
\hline \multicolumn{6}{|c|}{ L18 $(2 * 3)$ Orthogonal Array } \\
\hline Sr. & Voltage & Pulse ON Time & Pulse OFF Time & Current & Bed Speed \\
\hline No. & Volts & $\mu \mathrm{sec}$ & $\mu \mathrm{sec}$ & Amps & $\mu \mathrm{m} / \mathrm{sec}$ \\
\hline 1 & 75 & 25 & 9 & 2 & 75 \\
\hline 2 & 75 & 25 & 12 & 4 & 150 \\
\hline 3 & 75 & 25 & 15 & 6 & 225 \\
\hline 4 & 75 & 35 & 9 & 2 & 150 \\
\hline 5 & 75 & 35 & 12 & 4 & 225 \\
\hline 6 & 75 & 35 & 15 & 6 & 75 \\
\hline 7 & 75 & 45 & 9 & 4 & 75 \\
\hline 8 & 75 & 45 & 12 & 6 & 150 \\
\hline 9 & 75 & 45 & 15 & 2 & 225 \\
\hline 10 & 100 & 25 & 9 & 6 & 225 \\
\hline 11 & 100 & 25 & 12 & 2 & 75 \\
\hline 12 & 100 & 25 & 15 & 4 & 150 \\
\hline 13 & 100 & 35 & 9 & 4 & 225 \\
\hline 14 & 100 & 35 & 12 & 6 & 75 \\
\hline 15 & 100 & 35 & 15 & 2 & 150 \\
\hline 16 & 100 & 45 & 9 & 6 & 150 \\
\hline 17 & 100 & 45 & 12 & 2 & 225 \\
\hline 18 & 100 & 45 & 15 & 4 & 75 \\
\hline
\end{tabular}

\section{RESULTS AND DISCUSSIONS}

\section{Experimental Results}

Taguchi developed a technique or method, which was built on traditional concepts of Design of Experiment (DOE). Orthogonal array (OA) is a specially constructed table used for the experimentation purpose, based on DOE technique to reduce the number of experiments, so as to give the optimum set of the preferred parameters. The L18 ( $2 * 3$ ) orthogonal array was chosen to conduct the experiment, as shown in table.

Table 3: Taguchi L18 Orthogonal Array Formulation 
The experiments were conducted in wet condition to study the effect of process parameters over the output response. The Experimental results for material removal rate and surface roughness are given in below table.

Table 4: Experimental Results

\begin{tabular}{|c|c|c|c|c|}
\hline \multicolumn{5}{|c|}{ L18 (2*3) Orthogonal Array } \\
\hline \multirow{2}{*}{ Sr. No. } & $\begin{array}{c}\text { Material Removal } \\
\text { Rate }\end{array}$ & S/N Ratio & Surface Roughness (Ra) & S/N Ratio \\
\cline { 2 - 5 } & $\mathbf{m m} / \mathbf{m i n}$ & $\mathbf{( d B )}$ & $\boldsymbol{\mu m}$ & $\mathbf{( d B )}$ \\
\hline 1 & 6.641 & 16.033 & 1.874 & -6.082 \\
\hline 2 & 17.651 & 25.530 & 1.53 & -4.862 \\
\hline 3 & 18.984 & 26.001 & 1.574 & -4.299 \\
\hline 4 & 14.895 & 23.587 & 1.739 & -5.976 \\
\hline 5 & 18.671 & 25.495 & 1.741 & -5.608 \\
\hline 6 & 6.906 & 16.642 & 1.400 & -3.482 \\
\hline 7 & 6.955 & 16.425 & 1.649 & -5.233 \\
\hline 8 & 18.886 & 16.814 & 1.569 & -4.901 \\
\hline 9 & 9.800 & 26.500 & 1.751 & -5.586 \\
\hline 10 & 29.99 & 19.980 & 1.409 & -3.966 \\
\hline 11 & 6.911 & 30.852 & 1.579 & -4.591 \\
\hline 12 & 18.483 & 25.583 & 1.600 & -5.550 \\
\hline 13 & 29.884 & 30.312 & 1.763 & -5.590 \\
\hline 14 & 6.88 & 16.837 & 1.619 & -5.741 \\
\hline 15 & 12.681 & 22.530 & 1.77 & -5.90 \\
\hline 16 & 18.862 & 26.390 & 1.462 & -4.527 \\
\hline 17 & 15.27 & 24.222 & 1.733 & -5.567 \\
\hline 18 & 6.877 & 16.833 & 1.505 & -4.258 \\
\hline
\end{tabular}

\section{Studies Related to Material Removal Rate}

Table 5: Analysis of Variance for MRR

\begin{tabular}{|l|c|c|c|c|c|}
\hline \multicolumn{1}{|c|}{ Source } & DF & Adj. SS & Adj. MS & F- Value & P- Value \\
\hline Voltage & 1 & 28.916 & 28.916 & 5.24 & 0.051 \\
\hline Pulse ON time & 2 & 9.179 & 5.090 & 0.80 & 0.484 \\
\hline Pulse OFF time & 2 & 81.259 & 38.729 & 7.72 & 0.014 \\
\hline Current & 2 & 119.535 & 61.167 & 11.74 & 0.004 \\
\hline Bed Speed & 2 & 55.390 & 27.795 & 5.20 & 0.036 \\
\hline Error & 8 & 42.062 & 6.133 & & \\
\hline \multicolumn{1}{|c|}{ Total } & $\mathbf{1 7}$ & $\mathbf{3 3 6 . 3 4 1}$ & & & \\
\hline
\end{tabular}

DF- degree of freedom; SS- sum of squares; MS- mean of squares; F- ratio of variance of a source to variance of error; $\mathbf{P}$ - determines the significance of factor at $95 \%$ confidence level

Table 6: Response Table for MRR

\begin{tabular}{|l|c|c|c|c|c|}
\hline Level & Voltage & Pulse ON time & Pulse OFF time & Current & Bed speed \\
\hline $\mathbf{1}$ & 21.78 & 20.48 & 22.89 & 19.45 & 16.36 \\
\hline $\mathbf{2}$ & 23.15 & 23.52 & 21.39 & 22.45 & 24.92 \\
\hline $\mathbf{3}$ & --- & 21.53 & 20.17 & 23.60 & 26.14 \\
\hline Delta & 1.36 & 1.91 & 2.35 & 3.17 & 5.79 \\
\hline Rank & $\mathbf{5}$ & $\mathbf{4}$ & $\mathbf{3}$ & $\mathbf{2}$ & $\mathbf{1}$ \\
\hline
\end{tabular}

The response table for material removal rate is given in Table 6. It gives the information regarding the factors that has the maximum effect on material removal rate. Bed speed has the maximum effect on material removal rate followed by 
Current, Pulse OFF time, Pulse ON time and Voltage in that order.

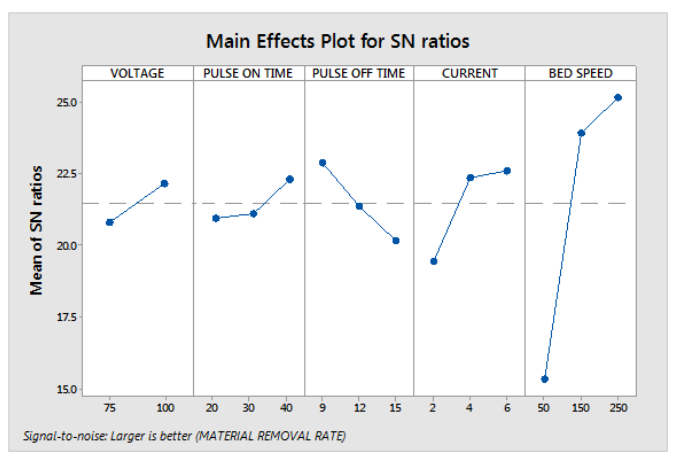

Figure 3: Effects of Process Parameters on S/N Ratio (Material Removal Rate)

Figure 3 shows the effect of process parameters on the material removal rate. The Material removal rate is the "Higher the Better" type quality characteristic. On the basis of the analysis, the S/N ratio for optimized process parameter for achieving better material removal rate while machining tool steel are Voltage :100 volts, Pulse ON time :40 $\mu$, Pulse OFF time :9 $\mu \mathrm{s}$, Current :6 amp, Bed Speed :250 $\mu \mathrm{m} / \mathrm{s}$.

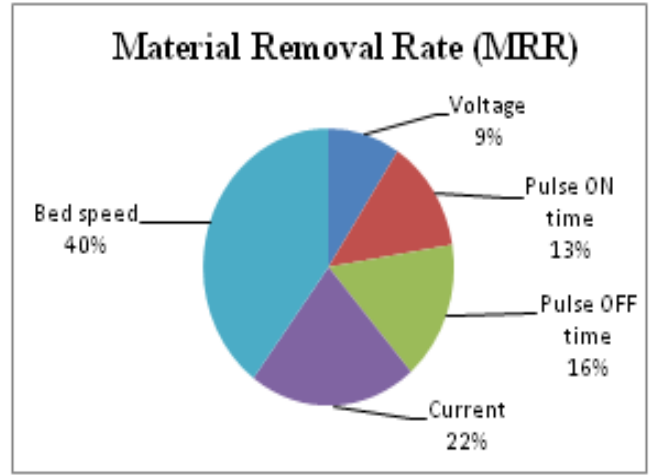

Figure 4: Percentage Contribution by Process on Material Removal Rate

It is observed from the above figure that Bed Speed contributes the most that is $40 \%$ followed by Current $22 \%$, Pulse OFF time 16\%, Pulse ON time 13\% and Voltage 9\% to achieve better Material Removal Rate in machining.

\section{Studies Related to Surface Roughness}

For measuring the surface roughness SURFEST SJ-210, portable surface measuring unit was used. A mean of three readings were taken at three different places, so that an error can be taken into account.

Table 7: Analysis of Variance for Surface Roughness

\begin{tabular}{|l|c|c|c|c|c|}
\hline \multicolumn{1}{|c|}{ Source } & DF & Adj. SS & Adj. MS & F- Value & P- Value \\
\hline Voltage & 1 & 0.031771 & 0.031771 & 0.59 & 0.483 \\
\hline Pulse ON time & 2 & 0.056366 & 0.042183 & 1.04 & 0.406 \\
\hline Pulse OFF time & 2 & 0.007854 & 0.004427 & 0.09 & 0.812 \\
\hline Current & 2 & 0.030519 & 0.011259 & 0.31 & 0.863 \\
\hline Bed Speed & 2 & 0.059394 & 0.033697 & 0.82 & 0.600 \\
\hline Error & 8 & 0.289155 & 0.045644 & & \\
\hline Total & 17 & 0.954118 & & & \\
\hline
\end{tabular}

DF- degree of freedom; SS- sum of squares; MS- mean of squares; F- ratio of variance of a source to variance of error; $\mathbf{P}$ - determines the significance of factor at $95 \%$ confidence level 
Table 8: Response Table for Surface Roughness

\begin{tabular}{|l|c|c|c|c|c|}
\hline Level & Voltage & Pulse ON time & Pulse OFF time & Current & Bed speed \\
\hline $\mathbf{1}$ & -5.240 & -5.107 & -5.124 & -5.273 & -4.794 \\
\hline $\mathbf{2}$ & -5.061 & -5.412 & -5.212 & -5.217 & -5.011 \\
\hline $\mathbf{3}$ & --- & -3.999 & -5.026 & -4.521 & -5.638 \\
\hline Delta & 0.190 & 0.489 & 0.189 & 1.312 & 0.395 \\
\hline Rank & $\mathbf{5}$ & $\mathbf{2}$ & $\mathbf{4}$ & $\mathbf{1}$ & $\mathbf{3}$ \\
\hline
\end{tabular}

Table 8 represents the response table for surface roughness. The ranks and delta values for parameters in the table show that Current has the greatest effect on surface roughness followed by the Pulse ON time, Bed Speed, Pulse OFF time, Voltage in that order.

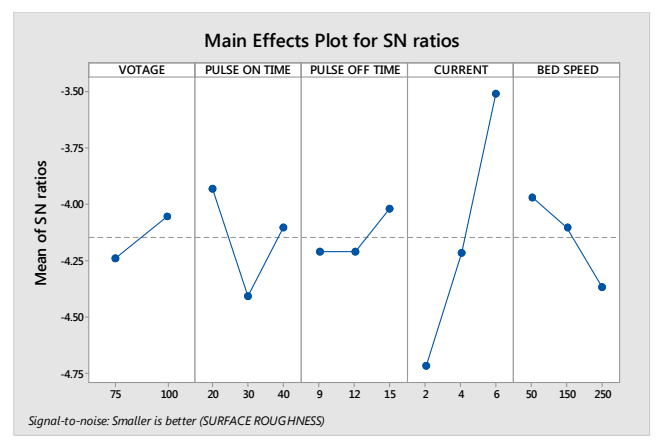

Figure 5: Effects of Process Parameters on S/N ratio (Surface Roughness)

Figure 5 shows the Effect of process parameters on main surface roughness. Surface Roughness has the "Lower the Better" type quality characteristic. On the basis of the analysis, the $\mathrm{S} / \mathrm{N}$ ratio for optimized process parameter for achieving better Surface Roughness (Ra) while machining tool steel are Voltage :75 volts, Pulse ON time :30 $\mu$, Pulse OFF time :9 $\mu$,

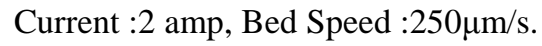

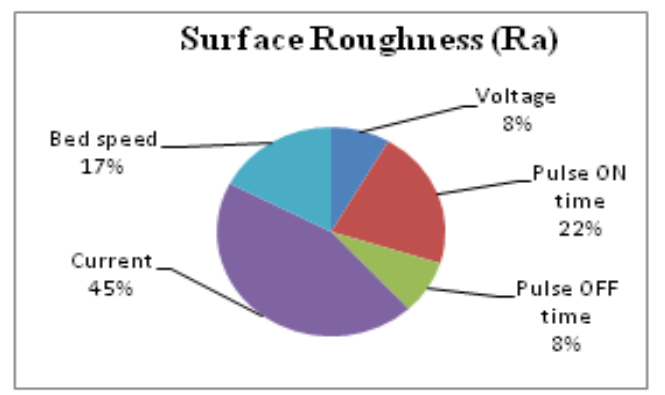

Figure 6: Percentage Contribution by Process on Surface Roughness

It is observed from the above figure that Current contributes the most, that is $45 \%$ followed by Pulse ON time $22 \%$, Bed Speed $17 \%$, Pulse OFF time $8 \%$, Voltage $8 \%$ in that order, to achieve better surface finish in machining.

\section{CONCLUSIONS}

Wire electric discharge performance characteristics are mainly evaluated on the basis of Material Removal Rate and Surface Roughness. In this experimentation work, D3 grade tool steel was the workpiece material and taguchi L18 orthogonal array was used. S/N ratio and ANOVA analysis were carried out to determine the effect of input parameters on the output parameters. 
Based on the analysis, the following conclusions were drawn:

- Using taguchi method MRR and Ra were optimized individually.

- $\quad$ For MRR, Bed Speed was the most influential parameter. Current, Pulse ON time, Pulse OFF time and Voltage were less influential parameters.

- Material Removal Rate can be maximized by selecting the following combination of the process parameters; Voltage-100 volts: Pulse ON Time-40 $\mu$ s: Pulse OFF time-9 $\mu$ s: Current-6 amps: Bed Speed-250 $\mu \mathrm{m} / \mathrm{s}$.

- For Surface Roughness, Current was the most influential parameter. Pulses ON time, Bed Speed, Pulse OFF time, Voltage were less significant factors.

- Good Surface finish can be obtained by selecting the following combination of the process parameters; Voltage75 volts: Pulse ON Time-30 $\mu$ s: Pulse OFF time-9 $\mu$ s: Current-2 amps: Bed Speed-250 $\mu \mathrm{m} / \mathrm{s}$.

\section{REFERENCES}

1. Selvakumar, G. Sornalatha, S. Sarkar, S. Mitra, "Experimental investigation and multi objective optimization of wire electrical discharge machining (WEDM) of 5083 aluminum alloy”, transactions of non ferrous metals society of china 24 , (2014), PP 373-379.

2. Rupesh Chalisgaonkar, Jatinder Kumar, "Multi response optimization and modeling of trim cut WEDM operation of commercially pure titanium (CPTi) considering multiple user's preferences", Engineering Science and Technology, an International Journal, (2014).

3. S. Sivakiran, C. Bhaskar Reddy, C. Eswara Reddy, "Effect of process parameters on Mrr in Wire Electrical Discharge Machining of En31 Steel", International Journal of Engineering Research and Applications, Vol. 2 (2012), pp 1221-1226.

4. H. Singh, R. Garg, "Effects of process parameters on material removal rate in WEDM", Journal of Achievements in Materials and Manufacturing Engineering, Vol. 22, Issue 1(2009), pp70-74.

5. Debashis Dey \& Rakesh, Optimization of the Tool Parameters in Ultrasonic Vibration Assisted Drilling by Taguchi Method, International Journal of Mechanical and Production Engineering Research and Development (IJMPERD), Volume 6, Issue 2, March - April 2016, pp. 1-10

6. Rodge M. K., Sarpate S. S., Sharma S. B., "Investigation of process response and parameters in wire electrical discharge machining of Inconel 625”, International Journal of Mechanical Engineering and Technology, Vol. 4, (2012), pp54-65.

7. Anoop Mathew Kurian, Dr. Binu C. Yeldose, Ernest Markose Mathew, "Effect of Wire EDM parameters on surface roughness of stainless steel 15-5 PH”, International Journal of Engineering and Innovative Technology, Vol. 4, (2014), pp 87-91.

8. Phadke, M. S., Quality Engineering using Robust Design, Pretience Hall, New Jersey, 1989.

9. P. C. Pandey, H. S. Shan, "Modern Machining Process", Tata McGraw-Hill Education, 1st edition 2008, pp 84-85. 